\title{
Impact of gestational diabetes mellitus diagnosed during the third trimester on pregnancy outcomes: a case-control study
}

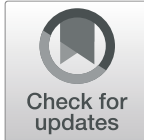

Ryosuke Shindo ${ }^{1}$, Shigeru Aoki ${ }^{1 *}$, Sayuri Nakanishi ${ }^{1}$, Toshihiro Misumi ${ }^{1,2}$ and Etsuko Miyagi ${ }^{3}$

\begin{abstract}
Background: In 2010, the International Association of Diabetes and Pregnancy Study Group (IADPSG) proposed new criteria indicating that gestational diabetes mellitus (GDM) can be diagnosed if the fasting threshold of $\leq 92 \mathrm{mg} / \mathrm{dL}$, 1 -h threshold of $\leq 180 \mathrm{mg} / \mathrm{dL}$, or 2-h threshold of $\leq 153 \mathrm{mg} / \mathrm{dL}$ are exceeded during the $75-\mathrm{g}$ 2-h oral glucose tolerance test (OGTT) performed at 24-28 weeks of gestation. The World Health Organization (WHO) recommends using the proposed diagnostic threshold values of the IADPSG to diagnose GDM; however, it does not limit the timing of the 75-g OGTT. Since 2010 in Japan, GDM has been diagnosed using the same criteria as that proposed by the WHO. However, neither the JSOG nor the WHO has provided any evidence that it is appropriate to use a threshold beyond the range recommended by the IADPSG.
\end{abstract}

Methods: This was a single-centre retrospective study based on the medical records and delivery registry database of our centre. We included women who underwent a 50-g glucose challenge test (GCT) with results $<140 \mathrm{mg} / \mathrm{dL}$ at 24-28 weeks of gestation and subsequently underwent a 75-g OGTT after 29 weeks of gestation with abnormal glucose tolerance suspected based on clinical findings. The reference values for the 75-g OGTT followed the IADPSG criteria. Subjects were classified into the normal glucose tolerance (NGT) group and the GDM group. The type of delivery and neonatal outcomes of the two groups were compared. A multivariable analysis was performed to match the backgrounds of both groups.

Results: In total, the NGT and GDM group comprised 189 and 49 women, respectively. Emergency caesarean delivery rates were similar in the GDM and NGT groups (10.6 and 12.2\%, respectively; adjusted odds ratio [OR], 1.25; 95\% confidence interval [CI], 0.43-3.64; $p=0.74)$; however, the elective caesarean delivery rate was higher in the GDM group than in the NGT group (16.3 and 5.3\%, respectively, adjusted OR, 3.60; 95\% Cl, 1.27-10.19; $p=0.01$ ). No significant differences were observed in other maternal and neonatal outcomes between both groups.

Conclusion: Although a diagnosis of GDM during the third trimester does not improve pregnancy outcomes, it increases the elective caesarean delivery rate.

Keywords: Gestational diabetes mellitus, International Association of Diabetes and Pregnancy Study Group, Third trimester, Late pregnancy, Caesarean delivery, Japan

\footnotetext{
*Correspondence: smyyaoki@yahoo.co.jp

'Perinatal Center for Maternity and Neonates, Yokohama City University

Medical Center, 4-57 Urafunecho, Minami-ku, Yokohama City, Kanagawa 232-0024, Japan

Full list of author information is available at the end of the article
}

(c) The Author(s). 2021 Open Access This article is licensed under a Creative Commons Attribution 4.0 International License, which permits use, sharing, adaptation, distribution and reproduction in any medium or format, as long as you give appropriate credit to the original author(s) and the source, provide a link to the Creative Commons licence, and indicate if changes were made. The images or other third party material in this article are included in the article's Creative Commons licence, unless indicated otherwise in a credit line to the material. If material is not included in the article's Creative Commons licence and your intended use is not permitted by statutory regulation or exceeds the permitted use, you will need to obtain permission directly from the copyright holder. To view a copy of this licence, visit http://creativecommons.org/licenses/by/4.0/ The Creative Commons Public Domain Dedication waiver (http://creativecommons.org/publicdomain/zero/1.0/) applies to the data made available in this article, unless otherwise stated in a credit line to the data. 


\section{Background}

Gestational diabetes mellitus (GDM) is associated with pregnancy and neonatal outcomes. Pregnant women with GDM are at a higher risk of having infants with large-for-gestational-age (LGA) status [1-3], preeclampsia $[4,5]$, shoulder dystocia [6-8], and neonatal morbidities [9], such as hypoglycaemia, hyperbilirubinemia, and respiratory distress syndrome (RDS) [10]. Furthermore, diagnosing and treating GDM contribute to improved delivery and neonatal outcomes $[3,4,11]$. The Hyperglycemia and Adverse Pregnancy Outcome (HAPO) study [2] showed that there was a linear relationship and no threshold for the association between maternal hyperglycaemia and adverse perinatal events. In 2010, the International Association of Diabetes and Pregnancy Study Group (IADPSG) proposed a new diagnostic criterion for GDM based on the results of the HAPO study: GDM can be diagnosed if the fasting threshold of $\leq 92 \mathrm{mg} / \mathrm{dL}$, 1 -h threshold of $\leq 180 \mathrm{mg} / \mathrm{dL}$, or 2 -h threshold of $\leq 153$ $\mathrm{mg} / \mathrm{dL}$ are exceeded during the 75-g 2-h oral glucose tolerance test (OGTT) performed at 24-28 weeks of gestation [12]. The World Health Organization (WHO) recommends using the proposed diagnostic threshold values of the IADPSG to diagnose GDM; however, it does not limit the timing of the 75-g OGTT [13]. In 2010, The Japan Society of Obstetrics and Gynaecology (JSOG) proposed that GDM be diagnosed using the thresholds recommended by the IADPSG without limiting the timing of the 75-g OGTT, similar to the WHO. However, neither the JSOG nor the WHO has provided any evidence that it is appropriate to use a threshold beyond the range recommended by the IADPSG. Therefore, this study aimed to determine the impact of diagnosing and treating GDM using the 75-g OGTT performed after 29 weeks of gestation, which is beyond the period recommended by the IADPSG, on delivery and neonatal outcomes.

\section{Methods}

\section{Research design and subject selection}

This was a single-centre, retrospective study based on the medical records and delivery registry database of our centre. This study was conducted with the approval of the Ethics Committee of Yokohama City University. Among women who delivered at our hospital between January 1, 2011 and December 31, 2019, we included those who underwent the 50 -g glucose challenge test (GCT) at 24-28 weeks of gestation with results $<140$ $\mathrm{mg} / \mathrm{dL}$ and subsequently underwent the 75-g OGTT after 29 weeks of gestation because of suspected abnormal glucose tolerance based on clinical findings, such as LGA, suspected macrosomia, polyhydramnios, and positive urine sugar levels. Women with multiple gestations were excluded. Similarly, women who had undergone previous caesarean deliveries were excluded because a previous caesarean delivery is a major factor determining future delivery procedures. Reference values for the 75-g OGTT were $92 \mathrm{mg} / \mathrm{dL}$ (fasting value), $180 \mathrm{mg} / \mathrm{dL}$ (1-h value), and $153 \mathrm{mg} / \mathrm{dL}$ (2-h value), as recommended by the IADPSG. GDM was diagnosed if any one of these values was exceeded. Subjects were classified into the normal glucose tolerance (NGT) group and the GDM group, and delivery and neonatal outcomes of these two groups were compared.

\section{GDM treatment}

When GDM was diagnosed, dietary therapy and blood glucose level monitoring using regular glycated haemoglobin $(\mathrm{HbA} 1 \mathrm{c})$ measurements or blood glucose measurements before and $2 \mathrm{~h}$ after meals were introduced. HbA1c target levels were $<6.2 \%$, and blood glucose target levels were $<100 \mathrm{mg} / \mathrm{dL}$ before meals and $<120 \mathrm{mg} / \mathrm{dL} 2 \mathrm{~h}$ after meals. Insulin therapy was introduced if the target blood glucose levels could not be achieved with dietary therapy.

\section{Characteristics and outcomes}

The following maternal characteristics were collected: age at delivery; height $(\mathrm{cm})$; pre-pregnancy weight $(\mathrm{kg})$; pre-pregnancy body mass index $\left(\mathrm{BMI} ; \mathrm{kg} / \mathrm{m}^{2}\right)$; weight at delivery $(\mathrm{kg})$; BMI at delivery $\left(\mathrm{kg} / \mathrm{m}^{2}\right)$; gestational weight gain $(\mathrm{kg})$; and number of previous deliveries. The main outcome was diabetes-related complications, which were defined as any one of the following: macrosomia, shoulder dystocia, neonatal hypoglycaemia, neonatal hyperbilirubinemia, or RDS. Other maternal outcomes were preeclampsia, initiation of insulin, caesarean delivery (overall), elective caesarean delivery, emergency caesarean delivery, and instrumental delivery. Secondary neonatal outcomes were LGA status, small for gestational age (SGA) status, low umbilical artery pH (UApH), low Apgar score (APS), neonatal intensive care unit (NICU) admission, birth weight (g), and gestational age (weeks).

\section{Term definitions}

A birth weight of $4000 \mathrm{~g}$ or more was defined as macrosomia. Shoulder dystocia was defined when the shoulder girdle could not be delivered spontaneously after delivery of the infant's head, and if the McRoberts position, suprapubic compressions, or vaginal manipulation were required. LGA status and SGA status were defined as being above the 90th percentile and being below the 10th percentile, respectively, according to the standard Japanese birth weight chart. Low UApH was defined as $<7.1$, and low APS was defined as $<7$ at $5 \mathrm{~min}$. Preeclampsia was defined as hypertension (systolic blood pressure $\geq 140 \mathrm{mmHg}$ or diastolic blood pressure $\geq 90$ $\mathrm{mmHg})$ accompanied by proteinuria $(0.3 \mathrm{~g} / \mathrm{gCr})$ that first appeared after 20 weeks of gestation and up to 12 weeks 
postpartum. Emergency caesarean delivery was defined as an attempted vaginal delivery resulting in the requirement for caesarean delivery for any reason during the progression of labour; it did not include cases of scheduled caesarean delivery. Neonatal hypoglycaemia was defined as blood glucose levels $<50 \mathrm{mg} / \mathrm{dL}$ for normal term infants and $<40 \mathrm{mg} / \mathrm{dL}$ for preterm infants. Neonatal hyperbilirubinaemia was assumed to require phototherapy for the child. RDS was diagnosed by a neonatologist using chest radiographs or microbubble tests and required the administration of a surfactant.

\section{Statistical analysis}

We used JMP PRO version 15 (SAS Institute Inc., Cary, $\mathrm{NC)}$ for statistical analyses. Data are presented as frequency or median and interquartile range (IQR). Comparisons of binary variables were performed with the chi-square test. Kruskal-Wallis test was performed to compare continuous variables; $p<0.05$ was considered statistically significantly different. Multivariable analysis was performed to adjust for maternal backgrounds, and logistic regression analysis was performed for binary variables. Multiple regression analysis was performed for continuous variables. The adjusted odds ratio (aOR) or adjusted regression coefficient (aRC) and 95\% confidence interval $(\mathrm{CI})$ of the GDM group were calculated using the NGT group as a reference with adjustment for confounding factors, such as maternal age, non-pregnant BMI, childbirth experience, and sex of the infant.

\section{Results}

The total number of deliveries after 22 weeks of gestation at our hospital during the study period was 10,548. Of these, 7076 patients underwent the 50-g GCT, and 5852 had normal results $(<140 \mathrm{mg} / \mathrm{dL})$. Among them, 268 patients underwent the 75-g OGTT after 29 weeks of gestation. Of them, 238 patients were included in the analysis, excluding 3 women with multiple gestations and 27 who had a previous caesarean delivery. Among these subjects, 189 and 49 women were in the NGT group and the GDM group, respectively (Fig. 1).

Table 1 summarises the maternal backgrounds of the two groups. The median ages at delivery were 32 years (IQR, 28-35 years) and 31 years (IQR, 28-35 years) in the NGT group and GDM group, respectively, with no significant difference observed between groups ( $p=$ 0.46). There were no differences in height, prepregnancy weight, and BMI. Weight at delivery was lesser in the GDM group than in the NGT group (60.6 $\mathrm{kg}$ [IQR, 56.5-69.9] and $64.6 \mathrm{~kg}$ [IQR, 58.6-71.1], respectively); however, the difference was not statistically significant $(p=0.14)$. Gestational weight gain was significantly lower in the GDM group than in the NGT group $(9.0 \mathrm{~kg}$ and $11.0 \mathrm{~kg}$, respectively; $p=0.02)$. There was a

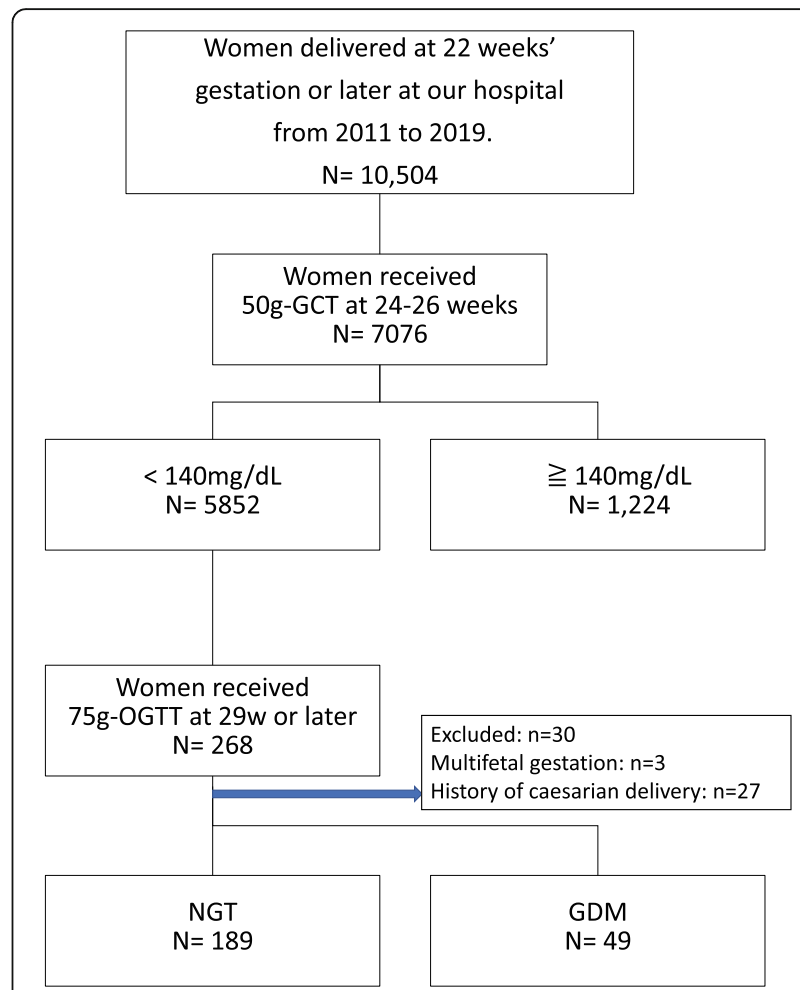

Fig. 1 Flowchart of subjects selection

higher proportion of male newborns in the GDM group than in the NGT group (71.4 and $51.8 \%$, respectively; $p=0.01)$. Three women $(6.1 \%)$ in the GDM group were treated with insulin.

Table 2 summarises the gestational and neonatal outcomes of both groups. The rates of diabetes-related complications were 13.8 and $18.4 \%$ in the NGT group and GDM group, respectively; this difference was not statistically significant (aOR, $1.31 ; 95 \% \mathrm{CI}, 0.56-3.06$; $p=0.53$ ). No statistically significant differences in the rates of macrosomia, shoulder dystocia, hypoglycaemia, or hyperbilirubinemia were observed between the two

Table 1 Characteristics of each group

\begin{tabular}{llll}
\hline & NGT $\boldsymbol{n}=\mathbf{1 8 9}$ & GDM $\boldsymbol{n}=\mathbf{4 9}$ & $\boldsymbol{p}$-value \\
\hline Maternal age (yo) & $32(28-35)$ & $31(28-35)$ & 0.46 \\
Maternal height $(\mathrm{cm})$ & $159(155-162)$ & $157(153-163)$ & 0.16 \\
Pre-pregnancy weight $(\mathrm{kg})$ & $52.8(48.0-58.0)$ & $50.6(47.0-57.5)$ & 0.47 \\
Pre-pregnancy BMI $(\mathrm{kg} / \mathrm{m} 2)$ & $20.7(19.2-22.5)$ & $20.5(18.8-22.8)$ & 0.90 \\
Weight at delivery $(\mathrm{kg})$ & $64.6(58.6-71.1)$ & $60.6(56.5-69.9)$ & 0.14 \\
BMl at delivery $(\mathrm{kg} / \mathrm{m} 2)$ & $25.4(23.5-27.6)$ & $24.9(22.4-27.8)$ & 0.48 \\
Gestational weight gain $(\mathrm{kg})$ & $11.0(8.9-13.8)$ & $9.0(7.2-12.8)$ & 0.02 \\
Multipara & $72(38.1)$ & $20(40.8)$ & 0.73 \\
Male newborns & $98(51.8)$ & $35(71.4)$ & 0.01 \\
Insulin treatment & $0(0)$ & $3(6.1)$ & - \\
\hline
\end{tabular}

Data are expressed as $\mathrm{n}(\%)$ or median (IQR Inter Quartile Range) 
Table 2 Pregnancy delivery and neonatal outcomes

\begin{tabular}{|c|c|c|c|c|c|}
\hline & \multirow{2}{*}{$\begin{array}{l}\text { NGT } \\
n=189\end{array}$} & \multicolumn{3}{|l|}{ GDM } & \multirow[t]{2}{*}{$P$ value } \\
\hline & & $n=49$ & ${ }^{\mathrm{a}} \mathrm{aOR}$ & $95 \% \mathrm{Cl}$ & \\
\hline 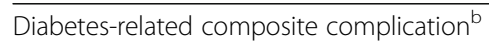 & $26(13.8)$ & $9(18.4)$ & 1.31 & $0.56-3.06$ & 0.53 \\
\hline Macrosomia & $10(5.3)$ & $3(6.1)$ & 0.98 & $0.25-3.86$ & 0.97 \\
\hline Shoulder dystocia & $6(3.2)$ & $3(6.1)$ & 1.6 & $0.37-6.85$ & 0.53 \\
\hline Hypoglycemia & $2(1.1)$ & $2(1.1)$ & 3.71 & $0.49-27.84$ & 0.2 \\
\hline Hyperbilirubinemia & $11(5.8)$ & $2(4.1)$ & 0.74 & $0.15-3.61$ & 0.71 \\
\hline RDS & 0 & 0 & - & - & - \\
\hline Preeclampsia & $11(5.8)$ & 0 & - & - & - \\
\hline Total caesarian delivery & $30(15.9)$ & $14(28.6)$ & 2.41 & $1.07-5.43$ & 0.03 \\
\hline Elective caesarian delivery & $10(5.3)$ & $8(16.3)$ & 3.6 & $1.27-10.19$ & 0.02 \\
\hline Emergency caesarian delivery & $20(10.6)$ & $6(12.2)$ & 1.25 & $0.43-3.64$ & 0.68 \\
\hline Instrumental delivery & $17(9.0)$ & $3(6.1)$ & 0.69 & $0.18-2.59$ & 0.58 \\
\hline Large for gestational age & $59(31.2)$ & $11(22.5)$ & 0.54 & $0.25-1.17$ & 0.12 \\
\hline Small for gestational age & $11(5.8)$ & $3(6.1)$ & 1.01 & $0.26-3.90$ & 0.99 \\
\hline Apgar score at $5 \mathrm{~min}<7$ & 0 & 0 & - & - & - \\
\hline UApH $<7.1$ & $3(1.6)$ & $2(4.1)$ & 2.55 & $0.39-16.50$ & 0.33 \\
\hline NICU admission & $9(4.8)$ & $4(8.2)$ & 1.68 & $0.48-5.86$ & 0.41 \\
\hline \multirow[t]{2}{*}{ Neonatal admission } & $17(9.0)$ & $5(10.2)$ & 1.07 & $0.37-3.15$ & 0.9 \\
\hline & & & ${ }^{\mathrm{a}} \mathrm{aRC}$ & & \\
\hline Neonatal weight (g) & $3222(2911-3541)$ & $3182(2949-3496)$ & -24 & $-97-49$ & 0.52 \\
\hline Gestational age at delivery (weeks) & $39.6(38.7-40.6)$ & $39.6(38.7-40.4)$ & 0.04 & $-0.16-0.24$ & 0.69 \\
\hline
\end{tabular}

Data are expressed as median (IQR) or $\mathrm{n}(\%)$

${ }^{a} a O R / a R C$ Adjusted Odds ratio/ regression coefficient, adjusted for maternal age, non-pregnant BMl, childbirth experience, and sex of the infant

${ }^{b}$ Diabetes-related composite complication was defined as any one of the following: macrosomia, shoulder dystocia, neonatal hypoglycaemia, neonatal hyperbilirubinemia, or RDS

groups. None of the infants developed RDS. The overall caesarean delivery rate was significantly higher in the GDM group than in the NGT group (28.6 and $15.9 \%$, respectively; aOR, 2.41; 95\% CI, 1.07-5.43; $p=0.04)$. Similarly, the rate of elective caesarean deliveries was higher in the GDM group than in the NGT group (16.3 and $5.3 \%$, respectively; aOR, 3.60; 95\% CI, 1.27-10.19; $p=$ 0.01 ). However, the rates of emergency caesarean deliveries were not significantly different between groups (10.6\% for the GDM group and $12.2 \%$ for the NGT group; aOR, $1.25 ; 95 \% \mathrm{CI}, 0.43-3.64 ; p=0.74)$. The median birth weights were $3222 \mathrm{~g}$ (IQR, 2911-3541 g) in the NGT group and $3189 \mathrm{~g}$ (IQR, 2949-3496 g) in the GDM group; however, no significant difference was observed between both groups (aRC, - 13.3; 95\% CI, - 83$56 ; p=0.71)$. The rates of LGA status were $31.6 \%$ in the NGT group and $24.0 \%$ in the GDM group, which were higher than the general rates; however, no significant difference was observed between groups $(p=0.20)$. The rates of SGA status were lower than the general rates of $5.2 \%$ in the NGT group and $6.0 \%$ in the GDM group; however, the difference was not significant. Additionally, no significant differences in low APS, low UApH, and NICU admission rates were observed between groups.

\section{Discussion}

This study showed that the frequency of diabetes-related composite complications for women diagnosed with GDM during the third trimester did not differ from that of pregnant women with NGT. More cases of elective caesarean deliveries were observed in the GDM group than in the NGT group; however, the rates of emergency caesarean deliveries were not significantly different between groups.

In this study, the rates of diabetes-related composite complications did not differ between women with GDM diagnosed and treated during the third trimester and women with NGT. However, diagnosing GDM and initiating interventions during the later stages of pregnancy may be too late to improve delivery outcomes. Limited reports have examined the effectiveness of diagnosing GDM and initiating interventions during late pregnancy. Arbib et al. reported a single-centre, retrospective study of pregnant women who underwent the 100-g 3-h 
OGTT during the third trimester despite normal 50-g GCT results. They reported that the group diagnosed with and treated for GDM during the third trimester birthed infants with lower birth weights than the NGT group; however, no difference in caesarean delivery rates or other outcomes was observed between groups [14]; the previous study results contradicted those of the present study. Differences in diagnostic criteria may have significantly contributed to this. Diagnosing and treating GDM after 29 weeks of gestation using the IADPSG criteria did not appear effective in this study.

It remains unknown whether the IADPSG criteria developed based on the results of the HAPO study of pregnant women between 24 and 32 weeks of gestation can be applied to different weeks of gestation to correctly detect abnormal glucose tolerance or pregnant women at high risk. Furthermore, OGTT results have been reported to vary according to the weeks of gestation $[15,16]$.

This study showed that more elective caesarean deliveries were performed for the GDM group than the NGT group. In Japan, GDM with an estimated foetal weight of more than $4000 \mathrm{~g}$ are indications for allowing patients to choose a scheduled caesarean delivery to avoid shoulder dystocia [17]. At our institution, we follow this policy and perform elective caesarean deliveries at the request of the patients. We speculated that a diagnosis of GDM also allows clinicians to select caesarean delivery to avoid shoulder dystocia because our data showed higher elective caesarean delivery rates but equivalent emergency caesarean delivery rates in the GDM group. Increased caesarean delivery rates for pregnant women diagnosed with GDM during late pregnancy have been reported by a previous study by Sasson et al., who reported that in a retrospective study of pregnant women who underwent the 100-g 3-h OGTT after 37 weeks of gestation despite normal GCT results during mid-pregnancy, there was a higher caesarean delivery rate in the GDM group; however, other pregnancy delivery outcomes were unchanged [18]. Fonseca et al. reported a prospective study of the 75-g 2-h OGTT performed at 32-36 weeks of gestation for pregnant women with normal glucose tolerance screening results during mid-pregnancy (with results withheld) to observe differences in delivery outcomes [19]. Forty-five of 334 pregnant women (13.5\%) had abnormal OGTT results at $32-36$ weeks of gestation, and they had more induced deliveries and caesarean deliveries than women with normal results. However, there were no differences in child size or neonatal outcomes. The results of this previous study are consistent with those of the present study because it used the IADPSG criteria and higher caesarean delivery rates were observed in the abnormal OGTT group; however, they differ from those of the current study because the results were blinded and the group with abnormal values was not treated.
This is the first study to examine the delivery outcomes of pregnant women diagnosed with and treated for GDM after 29 weeks of gestation using the same thresholds as the IADPSG criteria.

This study had several limitations. First, selection bias may have existed in this study because it was a singlecentre, retrospective study with small sample size. Second, the long-term prognoses of both mothers and children have not been studied. Pregnant women with GDM are at increased risk for metabolic syndrome [20], type 2 diabetes [21], and cardiovascular disease [22]. Similarly, GDM is considered to affect future metabolic abnormalities and neurodevelopmental prognoses of children [23-26].

\section{Conclusion}

In this study, the rates of diabetes-related composite complications of pregnant women diagnosed with GDM during the third trimester were not different from those of pregnant women with NGT. However, the rate of elective caesarean delivery was higher in the group diagnosed with GDM during late pregnancy than in the NGT group. These results may have been influenced by the fact that pregnant women with GDM and suspected LGA foetuses were given the option of elective caesarean delivery. Further studies of the significance of diagnosing and treating GDM during late pregnancy are warranted.

\section{Abbreviations \\ IADPSG: International Association of Diabetes and Pregnancy Study Group: GDM: Gestational Diabetes Mellitus,; OGTT: Oral Glucose Tolerance Test; WHO: World Health Organization; GCT: Glucose Challenge Test; NGT: Normal Glucose Tolerance; OR: Odds Ratio; RC: Regression Coefficient; aOR: Adjusted Odds Ratio.; aRC: Adjusted Regression Coefficient; Cl: Confidence Interval; LGA: Large for Gestational Age; SGA: Small for Gestational Age; HAPO: Hyperglycaemia and Adverse Pregnancy Outcome; JSOG: Japan Society of Obstetrics and Gynecology; BMI: Body Mass Index; \\ GWG: Gestational Weight Gain; RDS: Respiratory Distress Syndrome; UA: Umbilical artery; APS: Apgar score; NICU: Neonatal Intensive Care Unit}

\section{Acknowledgements}

Not applicable.

Authors' contributions

R.S. wrote the initial draft of the manuscript. S.N. assisted in writing the manuscript. T.M. contributed to analysis and interpretation of data. S.A. designed the study and assisted in the preparation of the manuscript. E.M. contributed to the review of the manuscript and the final approval of the version to be published. All other authors have contributed to data collection and interpretation and critically reviewed the manuscript. All authors approved the final version of the manuscript and agreed to be accountable for all aspects of the work in ensuring that questions related to the accuracy or integrity of any part of the work are appropriately investigated and resolved.

\section{Funding}

Not applicable.

Availability of data and materials

The datasets used and/or analysed during the current study are available from the corresponding author on reasonable request. 


\section{Declarations}

\section{Ethics approval and consent to participate}

This study was conducted with the approval of the ethics committee of Yokohama City University (No. B180700036). The need for informed consent was waived due to the retrospective nature of this study. Instead, the study was displayed on the hospital's website, and the opportunity to withdraw consent was given.

\section{Consent for publication}

Not applicable.

\section{Competing interests}

The authors declare that they have no competing interests.

\section{Author details}

${ }^{1}$ Perinatal Center for Maternity and Neonates, Yokohama City University Medical Center, 4-57 Urafunecho, Minami-ku, Yokohama City, Kanagawa 232-0024, Japan. ${ }^{2}$ Department of Biostatistics, Yokohama City University Graduate School of Medicine, Yokohama, Japan. ${ }^{3}$ Department of Obstetrics and Gynecology, Yokohama City University School of Medicine, Yokohama, Japan.

Received: 6 October 2020 Accepted: 17 March 2021

Published online: 24 March 2021

\section{References}

1. Kwik M, Seeho SK, Smith C, McElduff A, Morris JM. Outcomes of pregnancies affected by impaired glucose tolerance. Diabetes Res Clin Pract. 2007;77: 263-8.

2. Metzger BE, Lowe LP, Dyer AR, Trimble ER, Chaovarindr U, Coustan DR, et al. Hyperglycemia and adverse pregnancy outcomes. N Engl J Med. 2008;358: 1991-2002.

3. Crowther CA, Hiller JE, Moss JR, McPhee AJ, Jeffries WS, Robinson JS. Effect of treatment of gestational diabetes mellitus on pregnancy outcomes. N Engl J Med. 2005;352:2477-86.

4. Yogev $Y$, Xenakis EM, Langer $\mathrm{O}$. The association between preeclampsia and the severity of gestational diabetes: the impact of glycemic control. Am J Obstet Gynecol. 2004;191:1655-60.

5. Yogev, Chen, Hod, Coustan, Oats, Mclntyre, et al. Hyperglycemia and Adverse Pregnancy Outcome (HAPO) study: preeclampsia. Am J Obstet Gynecol. 2010;202:255.e1-7.

6. Nesbitt TS, Gilbert WM, Herrchen B. Shoulder dystocia and associated risk factors with macrosomic infants born in California. Am J Obstet Gynecol. 1998:179:476-80.

7. Acker DB, Sachs BP, Friedman EA. Risk factors for shoulder dystocia. Obstet Gynecol. 1985;66:762-8.

8. Sandmire HF, O'Halloin TJ. Shoulder dystocia: its incidence and associated risk factors. Int J Gynaecol Obstet. 1988;26:65-73.

9. Hod M, Merlob P, Friedman S, Schoenfeld A, Ovadia J. Gestational diabetes mellitus. A survey of perinatal complications in the 1980s. Diabetes. 1991; 40(Suppl 2):74-8.

10. Bourbon JR, Farrell PM. Fetal lung development in the diabetic pregnancy. Pediatr Res. 1985;19:253-67.

11. Langer $\mathrm{O}$, Rodriguez DA, Xenakis EM, McFarland MB, Berkus MD, Arrendondo F. Intensified versus conventional management of gestational diabetes. Am J Obstet Gynecol. 1994;170:1036-46 discussion 46-7.

12. Metzger BE, Gabbe SG, Persson B, Buchanan TA, Catalano PA, Damm P, et al. International association of diabetes and pregnancy study groups recommendations on the diagnosis and classification of hyperglycemia in pregnancy. Diabetes Care. 2010;33:676-82.

13. World Health Organization. Diagnostic Criteria and classification of Hyperglycemia first detected in pregnancy. https://apps.who.int/iris/bitstrea m/handle/10665/85975/WHO_NMH_MND_13.2_eng.pdf;sequence=1

14. Arbib N, Gabbay-Benziv R, Aviram A, Sneh-Arbib O, Wiznitzer A, Hod M, et al. Third trimester abnormal oral glucose tolerance test and adverse perinatal outcome. J Matern Fetal Neonat Med. 2017;30:917-21.

15. Iwama N, Sugiyama T, Metoki H, Kusaka H, Yaegashi N, Sagawa N, et al. Difference in the prevalence of gestational diabetes mellitus according to gestational age at 75-g oral glucose tolerance test in Japan: the Japan assessment of gestational diabetes mellitus screening trial. J Diabetes Invest. 2019;10:1576-85.

16. Nakanishi S, Aoki S, Kasai J, Shindo R, Obata S, Hasegawa Y, et al. High probability of false-positive gestational diabetes mellitus diagnosis during early pregnancy. BMJ Open Diabetes Res Care. 2020;8:e001234.

17. Kawaguchi R, Matsumoto K, Akira S, Ishitani K, Iwasaku K, Ueda Y, et al. Guidelines for office gynecology in Japan: Japan Society of Obstetrics and Gynecology (JSOG) and Japan Association of Obstetricians and Gynecologists (JAOG) 2017 edition. J Obstet Gynaecol Res. 2019;45:766-86.

18. Mohr Sasson A, Shats M, Goichberg Z, Mazaki-Tovi S, Morag I, Hendler I. Oral glucose tolerance test for suspected late onset gestational diabetes. J Matern Fetal Neonatal Med. 2019;18:1-5.

19. Fonseca A, Lopes J, Clode N. Glucose intolerance in the third trimester is not predictive of adverse outcomes. Int J Gynaecol Obstet. 2019;147:108-14.

20. Varner MW, Rice MM, Landon MB, Casey BM, Reddy UM, Wapner RJ, et al. Pregnancies after the diagnosis of mild gestational diabetes mellitus and risk of cardiometabolic disorders. Obstet Gynecol. 2017;129:273-80.

21. Bellamy L, Casas JP, Hingorani AD, Williams D. Type 2 diabetes mellitus after gestational diabetes: a systematic review and meta-analysis. Lancet. 2009; 373:1773-9.

22. Retnakaran R, Shah BR. Mild glucose intolerance in pregnancy and risk of cardiovascular disease: a population-based cohort study. CMAJ. 2009;181: 371-6.

23. Ornoy A. Growth and neurodevelopmental outcome of children born to mothers with pregestational and gestational diabetes. Pediatr Endocrinol Rev. 2005:3:104-13.

24. Ornoy A, Wolf A, Ratzon N, Greenbaum C, Dulitzky M. Neurodevelopmental outcome at early school age of children born to mothers with gestational diabetes. Arch Dis Child Fetal Neonatal Ed. 1999;81:F10-4.

25. Riggins T, Miller NC, Bauer PJ, Georgieff MK, Nelson CA. Consequences of low neonatal iron status due to maternal diabetes mellitus on explicit memory performance in childhood. Dev Neuropsychol. 2009;34:762-79.

26. Rizzo TA, Dooley SL, Metzger BE, Cho NH, Ogata ES, Silverman BL. Prenatal and perinatal influences on long-term psychomotor development in offspring of diabetic mothers. Am J Obstet Gynecol. 1995;173:1753-8.

\section{Publisher's Note}

Springer Nature remains neutral with regard to jurisdictional claims in published maps and institutional affiliations.

Ready to submit your research? Choose BMC and benefit from:

- fast, convenient online submission

- thorough peer review by experienced researchers in your field

- rapid publication on acceptance

- support for research data, including large and complex data types

- gold Open Access which fosters wider collaboration and increased citations

- maximum visibility for your research: over $100 \mathrm{M}$ website views per year

At BMC, research is always in progress.

Learn more biomedcentral.com/submissions 